\title{
Reflections on Being a Successful Academic Researcher
}

\author{
Shaun Pather and Dan Remenyi \\ University of the Western Cape \\ spather@uwc.ac.za \\ dan.remenyi@gmail.com \\ DOI: 10.34190/JBRM.17.2.01
}

\begin{abstract}
Research is central to the life of the career academic. However, the framework in which academic research is conducted is not generally well understood and neither is it often articulated or discussed. The literature tends to rather focus on issues in relation to specific research methodologies and the evaluation thereof. Additionally, previous research argues that it is common for university academics to have little or no formal preparation for their role as teachers. This paper posits that the same applies to that of the academic's role as a researcher. It cannot be assumed that the mere obtaining of a Doctoral degree, prepares the novice academic for a research career. Early career academics are expected to acquire an understanding of how to survive as a researcher through a process more related to osmosis than to the principles of academic discourse. This paper commences with an overview of the origins of the academic career and the doctoral degree. Thereafter, it introspects the requirements to be a successful academic researcher. Aspects of the academic researcher's agency in relation to personal values, characteristics, integrity, research uptake skills, as well as the benefits and challenges of a research career are explored. By unpacking the salient elements of what is required to be a successful academic researcher, this paper provides a basis for those who are considering a career in academe to make an assessment if such a pursuit is feasible. In addition, the paper provides a yardstick by which early or even mid-career academic researchers may judge their progress towards being a successful researcher, thereby identifying areas for improvement.
\end{abstract}

Keywords: Researcher, PhD, Academic, Career, Success, Challenges, Research uptake, Research quality

\section{Introduction: Background and Context}

In the current era the importance of research in the life of an academic is paramount. Several studies have been conducted over the years into the issues related to the academic research function, its pitfalls and its challenges (Drennan, 2001; McAlpine and Amundsen, 2015; Browning, Thompson and Dawson, 2017). Moreover, expectations around success in academia vary, and early career academics often receive conflicting messages about what they should concentrate on to achieve promotion or tenure (Sutherland, 2017).

In order to contextualise the research function of the academic we briefly reflect on the historical perspective of how the university system evolved, and that of the emergence of the doctoral research degree. This provides the backdrop to the underlying problem of the tension inherent in the life of the average academic, in which a balance must be found between being a successful researcher and that of other prerogatives of the academic career.

\subsection{A brief history of the University System and the Evolvement of the Research Degree}

It is interesting that universities in the Western world generally trace their ancestry back to the University of Bologna in 1088. After Bologna, the first university to be established by a definite act was the Castilian University of Palencia, founded by Alfonso VIII of Castile in 1208-9 (Cobban, 1988). This University and the others established in the ensuing 300 years were centres of scholarship where the emphasis was on the preparation of individuals for the professions. At that time the main professions which were being addressed related to the church i.e. theology, the law, medicine, teaching and science.

As well as being centres of teaching and learning there were of course some research activities. Great names like Galileo Galilei and Isaac Newton were based at distinguished universities in Italy and England. However, the emphasis of university activities was not on research for the creation of new knowledge per se. The universities were centres of scholarship which, in former times, meant learning and reflecting on what was already known. In these early days there was a struggle to disconnect knowledge from the notion that it was a direct gift from "The Almighty". Galileo famously announced that the Judaeo-Christian scriptures informed human kind "How to go to heaven, rather than how the heaven go!" (Gingerich, 1982: 134). The research 
mentality which is common today was yet to be incarnated into the university system which was still quite some hundreds of years away from the concept of research being central to the academic project.

It was only in the $19^{\text {th }}$ century, with the thirst for new technology in the industrial revolution, that the research degree was invented. The PhD was created in Germany but soon spread to the United States of America and not long after that to the United Kingdom and then to other countries (Bourner, Bowden and Laing, 2001). Originally the PhD was seen primarily as a licence to teach and as such was as much about scholarship as research. However, eventually the emphasis was transferred to original research, distinctly based within a framework of scholarship. For six centuries, professional doctorates in theology, law and medicine were preeminent. By contrast, the modern Doctor of Philosophy, the PhD (or DPhil), originated in Berlin University in the early part of the nineteenth century after which it then spread across the German universities, attracting students from many other countries, notably the USA (Bourner, Bowden and Laing, 2001). The PhD has since become the gateway degree into the academic profession. As such, one of the key processes linked to the emergence of the knowledge economy as we know it today is the shift in the purpose of the Ph.D. from being a licence to teach in academic institutions to being an important strategic resource for a country's economic development (Herman, 2012:1).

\subsection{The centralisation of research in academe}

It is important to note that, although originally focused on teaching, the academic profession, by the late nineteenth and early twentieth centuries, had evolved into a dual one (in Germany much earlier than in the United States and the UK) comprising both teaching and research (Kreber, 2010). It is also worth mentioning that although the origin of papers published in scientific journals can be traced back to at least the Royal Society in 1665 (Atkinson, 1988) they were not a major feature of university activity until a number of centuries later. It has really only been since the second half of the $20^{\text {th }}$ century that there has been compunction on academics to be involved in research. As a consequence the review process rose to the fore (Spier, 2002) and academics were compelled to have the findings of their research projects published in double-blind peer reviewed journals. But even then it cannot be argued that the pressure was significant and many academics enjoyed highly satisfactory careers with very few publications to their name.

By the beginning of the $21^{\text {st }}$ century the attitude of the Academy began to change and the requirement to publish had become a central issue for all academics. Today the pressure has significantly increased and many academics complain that research is now seen by far too many academic administrators as being more important than teaching (Rawat and Meena, 2014). This has come about because of the need to seek new paradigms for university funding (Weiler, 2000). Many universities are therefore often directly affected by the quantity and the quality of their research output. The pressure is now so great on the quantity of publishing (De Rond and Miller, 2005) that some have argued that this has resulted in a deterioration of attention to the quality of research being produced (Sarewitz, 2016). However, this point is at present highly contentious and there is concern that much of current research does deliver the type of value which it should.

Of course, where this research focus has been placed at the expense of attention to teaching (Drennan, 2001) and that of other student needs does not bode well for the University. At the end of the day universities have to remain centres whereby knowledge is disseminated and individual students are guided towards successful careers. Without this type of function universities will have lost their way and simply become sterile institutions.

\subsection{The tension between research and other elements of the academic project}

Given this brief background of the origins of universities, and the centralisation of research within the academic project, a career in academic research does not suit everyone. The initial years as an early career academic are challenging times as those new to the academy attempt to balance the three aspects of their role in terms of teaching, research and service, while also coming to terms with both overt and hidden expectations (McKay and Monk, 2017). However, for those who enjoy the challenge it can be a rewarding way to spend one's working life. It has to be appreciated that the substance of academic work is arduous (see for example McCormick and Barnes, 2008; Chen and Anderson, 2008), and that the researcher role has become more demanding (Kyvic, 2013). The new academic is faced with multiple, and sometimes competing, demands and expectations, which include learning the culture of the new academic institution; understanding the processes and policies for academic performance review; establishing meaningful and constructive mentoring 
relationships; creating a sustainable research agenda; and fostering the writing attitudes and strategies that promote turning research projects into publications (McCormick and Barnes, 2008).

It is known that there are varying levels of support to the academic researcher. In some instances academics are overloaded with teaching duties (Porter and Umbach, 2001) and therefore find it difficult to initiate and sustain the research component of their career. Furthermore the environment in which academic work is conducted has become increasingly competitive, especially with regards to funding. Much work goes into research projects which are never completed and as for research degrees there is a stunningly high rate of non-completion (Bourke et al., 2004; McCormack, 2005).

\subsection{Objective of this paper}

Previous research, e.g. Kane, Sandretto and Heath (2002), argues that it is common for university academics to have little or no formal preparation for their role as teachers. We argue that the same applies to that of the academic's role as a researcher. We cannot assume that the mere obtaining of a Doctoral degree, prepares the novice academic for a research career. There are several other important issues, which this paper focuses on, that become paramount for success.

This brings to the fore the core purpose of this paper, viz. an introspection of requirements to be a successful academic researcher. By unpacking the salient elements of what is required to be a successful academic researcher, this paper provides a basis for those who are considering a career in academe to make an assessment if such a pursuit is feasible. In addition, the paper provides a yardstick by which early or even midcareer academic researchers may judge their progress towards being a successful researcher, thereby identifying areas for improvement. In summary, this paper addresses the traits of an academic researcher which are relevant to acquire a university post, retain it and even gain promotion.

\section{Implications of the research function in an academic career: Beyond just research skills}

Success is a social construct such that no person's character, behaviours, actions, or qualities are inherently successful in and of themselves but rather, success is a label given to various actions (or the outputs of the actions) by others and/or by the person him- or herself (Sutherland, 2017). It is sometimes suggested that success as an academic researcher amounts to little more than having a command of research methodology and finding a suitable research question. Although these two conditions are indeed necessary for success there are many more issues involved which all academic researchers need to be aware of and be able to confidently work with. This is further complicated by the fact that the occupational context of academics is characterised by increasingly complex relationships between teaching, research and administration (Kreber, 2010). This complexity is highlighted by Chen and Anderson (2008:65) who provide a telling account of the life of an academic:

Being a professor, it turns out, is no easy task. Barely had I moved into a rented house in a different city when I learned that I was expected to write a major grant proposal detailing an extensive research plan for the next 3 years. Soon I learned about the endless demands of an academic position. Between research, writing, classes, supervision, meetings, and committees, I never seemed to have a break. The situation was exacerbated when my son was born in pre-tenure year 3. Now I am also seriously sleep deprived. On top of all this craziness, I carry a doubt deep inside: Am I ready to be "the Professor"? (Chen and Anderson, 2008:65)

It is probably true to say that each academic who undertakes research will bring his or her own mindset, own skills and own aspirations to the tasks which are necessary to navigate the complexity of academic life, and become successful in this endeavour. However, at the same time it is also possible to identify values, characteristics and approaches to this type of work which will facilitate the achievement of success.

\subsection{Personal values which motivate excellence in academic research}

In order to address the personal characteristics which are necessary for success in this field of endeavour it is worthwhile to discuss the types of values which academic researchers aspire to. In this instance values are defined as being deeply held beliefs which directly influence the thinking and the behaviour of the individual who possesses them. Beliefs refer to a person's subjective probability judgements concerning some 
discriminable aspect of his world; they deal with the person's understanding of himself and his environment (Fishbein and Ajzen, 1975: 131).

Everyone's thinking and behaviour can be understood as a result of values, of which there is a fairly wide range that lend themselves to the realm of academic research. We suggest the following principal values are involved in motivating excellence in academic research:

- $\quad$ The centrality of knowledge: The view that knowledge is an important dimension in developing and individual's capacity to live a full, useful and enjoyable life. For this reason, knowledge is important to both the individual and to the society in which he or she lives;

- Contextual relevance of research output: Knowledge is always contextual and that, what could be seen as knowledge in one society or by one group of individuals, could be seen as of no value by others;

- Understanding the impact of research: Although knowledge may have value in its own right without any consideration of what can be achieved with it, the application of knowledge in order to improve the conditions of life of individuals or societies is a highly important consideration;

- An appreciation of the extant literature: Respect for what has already been known is an important issue although at the same time it is essential to realise more recent understandings can make what was formerly regarded as completely certain to have been mistaken;

- Academic integrity: Respect for the time and effort required to research and the fair acknowledgment of the work of others. This issue is sometimes understood as being part of the greater issue of academic integrity;

- Dissemination of research: Knowledge should be shared both at an individual level and at the level of the scholarly community. Therefore the publishing of research findings is critical. Dissemination of research findings in a non-academic context is equally important to ensure improvements in the everyday world of industry and society at large;

- Being a sympathetic gatekeeper: Researchers should be prepared to help anyone who wishes to join the community of researchers and genuinely pursue the development of further knowledge. This is applicable to the role of the researcher as a doctoral supervisor, and that of a journal peerreviewer.

We argue that the seven values described above provide a foundation of the academic persona, which is a necessary pre-requisite for successful research.

\subsection{Personal characteristics which underpin research success}

With the seven personal values in mind it is now useful to consider the issue of which personal characteristics might be most valuable for anyone who wishes to pursue a career as an academic researcher. Personal characteristics have been found to be related to job satisfaction (Koustelios, 2001) and are described as antecedents to work commitment (Bashaw and Grant, 1994). We have identified several characteristics of the researcher, which are set out below:

- The essence of being curious: A high level of curiosity is essential for the academic researcher and this curiosity needs to be focused primarily on issues to do with how the world operates and why it does so. Other questions of who, when and where can also be important but in the academic environment how and why questions are often paramount;

- Being a life-long learner: Being prepared, if not delighted, to learn and also to unlearn is a requirement. The academic researcher is on a constant learning curve and understanding that there is never a point in time of "knowing it all" implies constantly being humble about your perceived level of expertness. As research is intrinsically a social activity it is important that researchers be interested in the works of colleagues even when it is not directly relevant to one's own research;

- An awareness of the multi-dimensional nature of research problems: First and foremost, it is necessary for the researcher to be aware of the vastness and/or complexity of the world in which he or she works. The world exists in terms of concepts and artefacts and these are in general multidimensional and require some considerable focus in order to appreciate the premise of the average research problem.

- Being measured in passing judgement: Not rushing to judgement but being careful to reserve one's opinion until one has a full command of all the possibilities of the situation being studied. Many of 
the challenges faced by academic researchers are complex and require an ability to work with "messy" situations and make decisions in the face of either not enough or even too much information. Being sceptical of explanations which are not grounded appropriately is critical;

- Withstanding criticism: The capacity to be able to take criticism, even sometimes very hard criticism is an important attribute if one is to succeed in the research endeavour. In addition, an academic should be able to constructively critique the work of others without causing offence;

- Understanding that good research takes time: Being prepared to commit to a long-term project from which no benefit will be seen for 1, 2, 3 or even more years is essential. Even relatively small projects can run for a number of years before they are finally finished;

- Developing resilience: Possessing the capacity to work in an environment where there is a high uncertainty as to the degree of success which can be achieved is an important characteristic. In some fields an experiment may extend over a substantial period of time, after which it is found that the original hypotheses were invalid;

- Resisting a lone-ranger syndrome: Being able to collaborate with others makes academic research both more enjoyable and generally more effective. In many instances evidence of collaboration with peers, both regionally and internationally is viewed positively when being evaluated for tenure or promotion;

- Self-confidence: Having confidence in one's own capabilities and being able to defend one's own achievements is essential. A confident mind set leads to a positive attitude to the research activity, however daunting it may appear, and consequently instils a drive for success;

- Command of writing: Having an interest in language and thus having a thorough command of academic writing in which the research findings will be presented. This is a difficult matter especially for academic researchers who have to publish in a language that is not a first language. Help may be sought with regards to proofreading but it is a contentious matter as to whether the editing of research findings should be permitted. Such editing can unfortunately change the intentions and meaning of the researcher.

The values and characteristics described in this section lend themselves to the development of agency (Barker, 2003) of the academic researcher. This provides a foundation for the pursuit of the actual work of research.

\section{The work of academic research}

Åkerlind (2008: 25-26) identified four "qualitatively different ways of understanding being a university Researcher", which included:

- fulfilling academic requirements, with research experienced as an academic duty;

- establishing oneself in the field, with research experienced as a personal achievement;

- developing oneself personally, with research experienced as a route to personal understanding;

- $\quad$ enabling broader change, with research experienced as an impetus for change to benefit a larger community.

Kyvik (2013) suggests that there are six tasks related to the academic researcher role viz. networking; collaboration; managing research; doing research; publishing research; and evaluation of research.

The foregoing indicates that the work of the academic researcher is quite broad, and therefore requires a sense of deep commitment and resilience to do justice to all of the above. We argue that the academic will need to assume the values and characteristics, described in the foregoing sections, which in turn leads to a pattern of work in the pursuit of excellence in academic research.

However, before commencing with the research activity, it is important to state that the actual work involved in any research project will depend on a considerable number of specific factors. These include, inter-alia, the topic being researched, the research question, the culture in which the research is taking place, the funders of the research, and the expectations of what is to be achieved as a result of the research.

With all of these contextual issues in mind there are still a number of generalisations which can be made. The list of work that we present should not be interpreted as representing a timeline as frequently work needs to be done simultaneously, with the researcher deftly multi-tasking on more than one task at a time. 
A pre-requisite to research, and often one of feasibility, relates to funding. Goldfarb (2008) suggests that academic careers may be a function of the type of funding received. As academic research can sometimes be costly it is important for the researcher to ensure that adequate funding is available in order to see the project through to an appropriate conclusion. In order to do this, it is important that the prospective researcher be realistic concerning costs of equipment and/or cost of accessing appropriate data. In some lines of research data acquisition has become either difficult or expensive or both and this should be understood and provision for this should be made early in the project.

The development of appropriate research questions have been described previously e.g. Agee (2009), Lipowski (2008). The researcher begins by carefully defining a suitable research question which is of intellectual interest as well as having some potential value in other aspects of the society. The research question will ideally have some relationship to matters which the academic community will have already been aware. In certain fields of study there is greater emphasis on the research question being derived from some sort of already known intellectual conundrum whereas in other topics the research question can be more original and thus primarily be of a practical nature.

Of fundamental importance is the review of the contemporary academic literature on the subject to be studied (Bolderston, 2008; Pan, 2016). The purpose of this is to establish what has already been known and also to obtain insights into how aspects of this study or similar studies have previously been researched. This gives the researcher some inkling of the types of research designs and methods which have already been found to be effective in this area of study. The literature review is a sine qua non for the acceptance of any academic research findings. To achieve the quality of literature review required it is essential that the academic researcher develop a high level of skill at reflection and expressing his or her thoughts in writing.

It is essential that if an empirical study is to be pursued the researcher does not take any information which has been presented either in the literature or in the collected evidence on face value. Any research finding should immediately be qualified with the question, "What is the evidence for that assertion?" For this reason a grasp of fundamental research rigour, such as the technique of triangulation is essential.

Because every academic researcher will have his or her own personal perspective, a guiding principle which is most effective in conducting sound academic research, is for the researcher to continually ask how else could the data or evidence at his or her disposal be interpreted by others? The purpose of this is to minimise the bias which will inevitably be present due to the quintessential subjective nature of all personal perspectives.

Much has been written over the years from a project management perspective in respect of scope creep e.g. Khan (2006) and Thakurta (2013). An important issue for the researcher to therefore consider is whether the scope of the work that is being embarked on is realistic. Academic researchers sometimes take on projects which are too big, either in scope or the depth is too much to be addressed for the purposes of a degree or a peer-reviewed academic paper. In this respect project management skills are helpful.

The epistemic imperative in the research endeavour implies that we can only produce, at a single point in time, the best approximation to the truth, rather than a claim that we are producing an absolute truth. The academic researcher is not in a position to look for proof of any theory concept or assertion. Academic researchers are in the business of finding the best possible explanation for phenomena given the current state of their knowledge of the world. This means that academic research effectively only delivers suggested theories or explanations and knowledge which may at some future time be shown to be incomplete or in some other way no longer valid.

Academic research is highly regulated in a number of ways, one of which is through the necessity to obtain relevant permissions from authorities who govern the conduct of ethical research. How this works in practice varies from one University to another but in all instances there are a number of universal principles which are applied. The first of these is that whatever research is undertaken the highest care must be exercised that no harm of any sort should come to anyone involved in the project. This applies both to informants who may be supplying data or evidence, any participant in an experiment as well as the researcher him or herself. The second major issue which is of concern is that no activity of the researcher should in any way bring the good name of the University into disrepute. It is essential that the ethics rules of the University be carefully complied with. 
Academic researchers who are prepared to be helpful to colleagues and students are often rewarded in a number of different ways. There is, among academics, an unspoken law of reciprocity and a general feeling that it behoves academics to be collegiate. Therefore, if a researcher is prepared to extend the courtesy of assistance, this should be returned on other occasions that may arise.

Lastly, as was pointed out in the list of characteristics of a successful researcher, research is essentially a social activity which involves people collaborating at a number of different levels. To be highly successful as an academic researcher it is important to develop appropriate social skills which will allow the community of researchers to extend a range of courtesies. This becomes increasingly important as the researcher advances in his or her field of study.

\section{Academic integrity}

Confidence in scientific progress provides the basis for the public support of research and as such the professional integrity of scientists is important to society (Korenman, et al., 1998). It has been suggested that "perverse incentives and hypercompetition are altering academic behaviour of researchers and universities, reducing scientific progress and increasing unethical actions" (Edwards and Roy, 2017, p. 51). An issue which therefore needs to be addressed in connection with long term academic success is that of academic integrity. This concept is difficult to define and is often discussed in terms of how integrity has been violated. A comprehensive definition of integrity is problematic as it has so many dimensions, but at its core is the notion of honesty and the ability to face up to situations where individuals or institutions do not behave in the way that they should. Besides honesty, integrity involves fairness, respect and responsibility. As a lecturer an academic is continually being faced with concerns which are directly affected by fairness, respect and responsibility as these issues are of paramount importance in the relationship between teacher and student. All these issues also apply to academic researchers.

In the research environment the situation is even more complex in that the academic researcher has also to consider his or her relationships with informants, sponsors, co-researchers, publishers to mention only some of the stakeholders involved. All the different stakeholders will have individual expectations concerning the behaviour of the researcher and what can be achieved by the research project and sometimes these can be complex and even contradictory and it behoves the researcher to be able to pay these situations adequate attention and where there is any conflict to resolve such situations.

Academe does not have a spotless record with regards to the maintenance of a high degree of integrity. There are many examples of a wide range of cheating which has occurred for as long as research has been conducted. Perhaps the most scandalous example of academic research cheating in the $20^{\text {th }}$ century was that of Professor Sir Cyril Burt (Gillie, 1977), who fraudulently invented informants and collaborators or co-workers and whose alleged "research findings" were influential in moulding the United Kingdom's government educational policy after the Second World War. What is particularly surprising about this case is that the frauds committed by this man were not exposed for more than 20 years after his death. The academic community trusted this man in a number of different ways without apparently any consideration for the inspection of the integrity of the work which he produced.

Academic integrity is under increasing pressure in the $21^{\text {st }}$-century due to the availability of material on or through the Internet and the Web. The extraordinary interconnectivity offered through the Internet is a temptation for some researchers to indulge in activities such as plagiarism. The World Wide Web with its ability to present apparently attractive solutions to academic challenges has resulted in increased unacceptable practices of which ghost writing is only one.

However, despite these transgressions and the new temptations facilitated by our current fascination with technology, it is reasonable to believe that the vast majority of researchers approach their endeavours with a high degree of concern for integrity which allows the greater community to trust academic research findings and pay close attention to the recommendations of academic researchers. Also the introduction of ethics protocols, and the procedures established by which they are acquired and granted, have reduced the possibility of research misbehaviour. This is not to say that this risk has been eliminated but that it is much less likely to occur. 


\section{Experience teaches: Towards a satisfactory research output profile}

There is an old aphorism dating back to Roman times when it was expressed experientia docet which translates as experience is the best teacher. This is particularly true in the academic research world. Novice academic researchers can find their first project to be extraordinarily difficult. This is especially true when it comes to writing a paper which is to be blind peer-reviewed by a quality academic journal. Solomon (2007, p. 3) argues that "peer review is generally seen as vital for the roles of forming an archive of knowledge and distributing rewards; it also plays a key role in validating the quality of research in a field but, as noted by Kumashiro, may also hamper disseminating new ideas and methods".

Therefore peer review may be viewed both positively and negatively, and so the idea of having to satisfy two or more critical reviewers can be extremely daunting. In addition, some reviewers have been known to be unpleasantly and unnecessarily critical, sometimes even giving offence. However, after the first few papers have been written, reviewed, improved and published most academic researchers no longer find this procedure as painful as it was originally. Although there is much benefit from attending courses and from reading the literature on how to conduct and write up academic research, at the end of the day research is an art which is much better learnt through experience. In fact, it is sometimes argued that academic research is a skill which can only be learnt by working alongside an accomplished practitioner and this notion is often presented as a justification for the method of relatively intensive personal supervision which is provided to all doctoral and some masters students.

Becoming a successful academic researcher takes time. To be referred to as a successful academic researcher would normally require that a material number of papers have been published in quality journals. In today's environment many universities are looking to their faculty to be published in three star journals (some university systems use a star system to rank journals according to impact factor; in other instances a star rating does not apply, but a minimum impact factor of a journal is a requirement when publishing). However, this is often optimistic as the competition to be published in these journals is intense and even two-star journals (in some cases it may be even one-star journals) are frequently regarded as perfectly adequate. The number of papers which need to be published before an academic researcher might be considered successful will vary enormously. It is probably fair to say that by the time five or six pieces of research have been concluded and published in respectable journals an academic researcher could consider him or herself a success.

There is a question of how long it should take to achieve a satisfactory level of output and this will vary. Some universities state that their faculty should be able to achieve the publishing of two papers a year while others are much more flexible and will not declare a number on a yearly basis but will expect several well-cited papers to be published over a reasonably short period of time, for example 3 or 5 years. The main issue here is that the university expects that academic research becomes a lifelong activity and that it is not seen as simply a hurdle over which a faculty member must jump to secure a position, tenure or promotion. Academic research is now seen by the universities, by society and even by some prospective students as being a high priority activity which is in an important way one of the marks of the quality of the University itself.

\section{Research uptake: Beyond academic dissemination of findings}

Academic researchers have been spurred by a "publish or perish" imperative. Consequently the balance of forces, from a research effort perspective, has been inequitably skewed towards the goal of publishing, with less effort toward the goal of ensuring the uptake of research output within society at large. This is reinforced by Estabrooks et al. (2008: 1067) who argue that "Traditionally, universities served as intelligence banks that were publicly funded in return for academic contributions to the betterment of science. This relationship helped sustain the traditional (ivory tower) view of the academy. It allowed self-determination of research agendas and it limited academic accountability to scientific disciplines rather than the public". They go on to suggest that current trends indicate a renegotiation of the actual social contract between science and society, which sees society as an active partner in the creation of socially robust (as opposed to reliable) knowledge (Estabrooks et al., 2008).

A consequence of this trend is that over recent years, one of the most important changes in attitude towards academic research has been the realisation that even the most significant findings are of little value unless they are widely disseminated. Whereas in the past findings of academic research were simply reported or 
published in scientific or scholarly journals the research community has realised that this was sufficient, and more emphasis is called for to deliver research findings to society.

The concept of uptake, in its strict literal sense means the act of accepting or taking up something on offer. This can be construed in various ways, including acceptance, or consumption. The Development Research Uptake in Sub-Saharan Africa (DRUSSA) programme, led by the Association of Commonwealth Universities, defines research uptake as "the processes by which knowledge generated through research finds its way to those who need it-be they practitioners (health workers, farmers, engineers, community workers) or policymakers in government and other agencies" (DRUSSA, 2012). DRUSSA draws a parallel with currently familiar terms such as 'research communication', 'research dissemination', 'research utilisation', and 'research into use' with that of research uptake.

Research uptake starts in the early stages of the research cycle, instead of a narrowly focused end-goal of dissemination. Boshoff (2012) emphasises utilisation in his description of research uptake as follows:

"the process whereby research findings enter the domains of intended but also unintended audiences. It is a complex process as the audiences can be multiple (practitioners, policymakers, scholars, general public, etc.); the notion of 'uptake'-which corresponds to 'utilisation'-can assume different meanings.... and a variety of modes exist whereby research can reach user audiences...."

The notion of "utilisation" as alluded to above, and the alignment to the "end user" communities who will incorporate "new knowledge" into their practical work is an important consideration for the academic researcher. Consequently one of the implications of research uptake for the academic researcher is that of stakeholder engagement. This calls for effective engagement with stakeholders throughout the research cycle, from problem conceptualisation to that of findings. Thus stakeholders are involved in the design of the research questions and communication about the research results are tailored to the needs of different stakeholders.

The inherent value proposition of research uptake is that the visibility of research outcomes are enhanced, which leads to a wider societal recognition of the researcher, which in turn may improve citation rate. The higher visibility of research in society and in popular media also enhances the university's image and brand, and eventually supports the attraction of more funding.

\section{The benefits of being an academic researcher}

There are many benefits of being an academic researcher. There is much satisfaction in discovering new knowledge. When this is communicated to the greater world through publication it can deliver a high degree of prestige to the researcher. Today this is often regarded as the principal benefit from this activity. In previous times academics would say that their career afforded them much freedom. However, with an increasing managerial approach to universities much of this freedom has been eroded.

In addition to this prestige it can be rewarding to work with novices and to be able to guide them towards a successful career. It is often said that hardly anyone can ever pay back the benefits they have received from their education. The way to acknowledge these benefits has sometimes been referred to as "paying forward" which effectively means helping others to achieve success in their own right.

Success as an academic researcher can bring substantial benefits to the University or the institution in which the researcher is employed. Government funding schemes are often based at least in part on research output. Research output also attracts commerce and industry that may commission research projects or perhaps offer opportunities to academic researchers to undertake consultancy assignments in other organisations. This can be of significant assistance to the major community of which the researcher is a part.

There are many types of career benefits which success as an academic researcher will deliver and these include obtaining an interesting job, being given tenure at certain universities, or even obtaining a promotion. Some universities are known to pay bounties to researchers when research papers are published in certain journals. 
Academic research skills can be transferable to other professional environments. This can have two outcomes, one of which is to make the researcher more attractive in the job market if he or she should wish to switch employment and the other is that research skills can be offered on the basis of consultancy assignments. These can sometimes be highly lucrative for academic researchers.

But perhaps the most important issue is that the processes involved in conducting academic research throughout the research life-cycle, i.e. from problem scoping to dissemination of findings. These are actually highly engaging activities which can in their own right deliver a high level of enjoyment.

\section{The drawbacks of being an academic researcher}

This paper would be an incomplete if it did not include some of the disadvantages of being an academic researcher. The issues described here are probably more pertinent to those who are considering a future career in academe.

At the outset, it is becoming increasingly difficult to find entry level academic research posts. This is a factor of the dwindling financial resources across many universities globally. Many of the posts that are available are not permanent appointments as they are pinned to term contracts which mean a degree of insecurity to those involved.

The next challenge is that it takes a considerable amount of time to be accepted as a part of the academic research community. A doctorate degree such as a PhD rather than a professional doctorate is required. In some cases, post-doctoral work is considered essential. Junior researchers are required to prove themselves through a material public occasion track record before they are given proper recognition. Of course this is no different to any other profession except that in academe the goalposts can sometimes be rather vague. For example, there is no universal agreement about how long a post-doctoral fellowship should last or how many papers a novice researcher should have before he or she would be considered a fully-fledged member of the academic research community.

There is sometimes a considerable amount of bureaucracy and red tape associated with academic research. It may be necessary to acquire permission before a particular type of research programme is commenced. Issues related to funding can be difficult. Many universities operate under very strict budgeting and in some cases it can be quite difficult to obtain even modest amounts of money to support academic research projects. This can be a major impediment to research success.

The Ethics Protocol is often regarded by academic researchers as quite burdensome and there is much debate as to how effective it is in actually controlling the execution of the research project. Although it has almost universally agreed that the requirement to obtain an ethics clearance from the University is essential there is a considerable amount of controversy with regards to how this is done in some instances. By their nature universities, like many large organisations, are risk averse and therefore when reviewing ethics proposals there is a tendency for them to behave in such a way that they appear to be micromanaging research projects. Of course this can never really be the case as the research activity will always be in the hands of the academic and any of those who are working alongside him or her. However, this approach can cause what is often considered to be a large amount of additional work for the academic researcher and produce what appears to be a significant delay in commencing the project.

Being a good researcher requires one to be an excellent project manager and administrator. Many academics who obtain their first grant are not prepared for the work involved in managing the grant. This involves copious amounts of administration, report writing, financial management, and team management. Consequently the academic researcher needs to be much more than just a good researcher.

Academic research is highly competitive. Although there are those who collaborate well and are prepared to help others there is probably at least an equal number of people who do not. Academics have been known to copy or steal ideas and this has led to some unpleasant situations. It is important that the goodwill of ones' colleagues is not taken for granted. Neither should academic researchers feel that everyone they encounter is out to take advantage of them in one way or another. There is a very fine line to be drawn between being 
open about one's research interests and the amount of progress that has been made, and not showing one's hand to potential rivals.

In general University faculty are now much more adequately remunerated than they were in the past, but there are still many occasions in which researchers and especially novice researchers are not well paid and whose conditions of employment are not entirely satisfactory. This has become a bigger problem due to the fact that an increasing number of universities have abandoned notion of tenure and that others have increased the number of contract workers who they find considerably easier to manage and to dispense off when necessary.

\section{Conclusion}

The point of departure of this paper was that over a course of several centuries, the modern university has evolved such that research is central to the life of the career academic. However, given the centrality of this function, there is insufficient discourse in respect of the nuances of the varying facets of the research function. This paper addresses this gap. It presents a set of values and characteristics which underpin that of agency of the researcher and we argue that research skills on its own do not contribute to success.

The paper further provides an overview of what the essence of research work entails. We introspect issues in relation to academic integrity and the vicissitudes involved in developing a satisfactory research profile. The paper further delves into the relatively new concept of research uptake, on which very little has been written to date. In doing so the paper provides a basis for entry level and even mid-career academic researchers to assess their progress towards being a successful researcher.

Following on this, the paper has provided an overview of both the benefits and challenges of being an academic researcher. An aspirant academic may therefore reflect on this to assess if an academic career is suitable. In fact, it is probably correct to state that academic research offers a particularly challenging career path, if not an outright difficult one, and that the physical rewards which normally accompany this type of career are often not great. However, success in academic research can deliver a particularly high degree of satisfaction and occasionally, academic researchers have been internationally celebrated and even become household names. For those who are really successful there is much to be gained.

\section{References}

Agee, J., 2009. Developing qualitative research questions: a reflective process. International Journal of Qualitative Studies in Education, 22(4), pp.431-447.

Åkerlind, G.S., 2008. An academic perspective on research and being a researcher: An integration of the literature. Studies in Higher Education, 33(1), pp.17-31.

Atkinson, D., 1998. Scientific discourse in sociohistorical context: The Philosophical Transactions of the Royal Society of London, 1675-1975. London: Routledge.

Barker, C., 2003. Cultural studies: Theory and practice. London: Sage.

Bashaw, R.E. and Grant, E.S., 1994. Exploring the distinctive nature of work commitments: Their relationships with personal characteristics, job performance, and propensity to leave. Journal of Personal Selling \& Sales Management, 14(2), pp.41-56.

Bolderston, A., 2008. Writing an effective literature review. Journal of Medical Imaging and Radiation Sciences, 39(2), pp.86-92.

Boshoff, N., 2012. Nelius Boshoff on Research Uptake Management. Development Research Uptake in Sub-Saharan Africa (DRUSSA). [online] Available at: http://www.DRUSSA.org/index.php?option=com_content\&view=article\&id=1318\%3Anelius-boshoff-on-researchuptake-management\&catid=206\%3Aword-of-the-moment\&ltemid=299\&lang=en [Accessed 15 June 2013].

Bourke, S., Holbrook, A., Lovat, T. and Farley, P., 2004, November. Attrition, completion and completion times of PhD candidates. In AARE Annual Conference, Melbourne (Vol. 28).

Bourner, T., Bowden, R. and Laing, S., 2001. Professional Doctorates in England. Studies in Higher Education, 26(1): 65-83

Browning, L. Thompson, K. and Dawson, D., 2017. From early career researcher to research leader: survival of the fittest? Journal of Higher Education Policy and Management, 39(4), pp. 361-377.

Chen, X. and Anderson, R.C., 2008. Reflections on becoming a successful researcher. Educational Psychology Review, 20(1), pp.65-70.

Cobban, A.B., 1988. The Medieval English Universities Oxford and Cambridge to c.1500. New York: Routledge

De Rond, M. and Miller, A.N., 2005. Publish or perish: bane or boon of academic life? Journal of Management Inquiry, 14(4), pp.321-329. 
Drennan, L.T., 2001. Quality assessment and the tension between teaching and research. Quality in Higher Education, 7(3), pp.167-178.

DRUSSA. 2012. What is Research Uptake? Development Research Uptake in Sub-Saharan Africa (DRUSSA). [online] Available at: http://www.DRUSSA.net/index.php?option=com_content\&view=article\&id=1273\&ltemid=365\&lang=en [Accessed 15 June 2013].

Edwards, M.A. and Roy, S., 2017. Academic research in the 21st century: Maintaining scientific integrity in a climate of perverse incentives and hypercompetition. Environmental Engineering Science, 34(1), pp.51-61.

Estabrooks, C.A., Norton, P., Birdsell, J.M., Newton, M.S., Adewale, A.J. and Thornley, R., 2008. Knowledge translation and research careers: Mode I and Mode II activity among health researchers. Research Policy, 37(6-7), pp.1066-1078.

Fishbein, M., and Ajzen, I., 1975. Belief, Attitude, Intention, and Behavior: An Introduction to Theory and Research. Reading, MA: Addison-Wesley.

Gillie, O., 1977. Did Sir Cyril Burt fake his research on heritability of intelligence? Part I. The Phi Delta Kappan, 58(6), pp.469-471.

Gingerich, O., 1982. The Galileo Affair. Scientific American, 247(2), pp.132-143.

Goldfarb, B., 2008. The effect of government contracting on academic research: Does the source of funding affect scientific output? Research Policy, 37(1), pp.41-58.

Herman, C., 2012. The Purpose of the Ph.D. - A South African Perspective. Higher Education Policy, 25(1): 1-18.

Kane, R., Sandretto, S., and Heath, C., 2002. Telling half the story: a critical review of research on the teaching beliefs and practices of university academics. Review of Educational Research, 72(2), 177-228.

Khan, A., 2006. Project scope management. Cost Engineering, 48(6), pp.12-16.

Korenman, S.G., Berk, R., Wenger, N.S. and Lew, V., 1998. Evaluation of the research norms of scientists and administrators responsible for academic research integrity. Jama, 279(1), pp.41-47.

Koustelios, A.D., 2001. Personal characteristics and job satisfaction of Greek teachers. International Journal of Educational Management, 15(7), pp.354-358.

Kreber, C., 2010. Academics' teacher identities, authenticity and pedagogy. Studies in Higher Education, 35(2), pp.171-194.

Kyvik, S., 2013. The academic researcher role: enhancing expectations and improved performance. Higher Education, 65(4), pp.525-538.

Lipowski, E.E., 2008. Developing great research questions. American Journal of Health-System Pharmacy, 65(17), pp.16671670.

McAlpine, L. and Amundsen, C., 2015. Early career researcher challenges: substantive and methods-based insights. Studies in Continuing Education, 37(1), pp 1-17.

McCormack, C., 2005. Is non-completion a failure or a new beginning? Research non-completion from a student's perspective. Higher Education Research \& Development, 24(3), pp.233-247.

McCormick, C. B., and Barnes, B. J., 2008. Getting started in academia: A guide for educational

psychologists. Educational Psychology Review, 20(1), 5-18.

McKay, L. and Monk, S. 2017. Early career academics learning the game in Whackademia. Higher Education Research \& Development, 36(6), pp. 1251-1263.

Pan, M.L., 2016. Preparing literature reviews: Qualitative and quantitative approaches. New York: Routledge.

Porter, S.R. and Umbach, P.D., 2001. Analyzing faculty workload data using multilevel modelling. Research in Higher Education, 42(2), pp.171-196.

Rawat, S. and Meena, S., 2014. Publish or perish: Where are we heading? Journal of Research in Medical Sciences: the Official Journal of Isfahan University of Medical Sciences, 19(2), p.87.

Sarewitz, D., 2016. The pressure to publish pushes down quality. Nature News, 533 (7602), p.147.

Solomon, D.J., 2007. The role of peer review for scholarly journals in the information age. Journal of Electronic Publishing, [e-journal] 10(1). http://dx.doi.org/10.3998/3336451.0010.107

Spier, R., 2002. The history of the peer-review process. TRENDS in Biotechnology, 20(8), pp.357-358.

Sutherland, K.A., 2017. Constructions of success in academia: an early career perspective. Studies in Higher Education, 42(4), pp. 743-759.

Thakurta, R., 2013. Impact of scope creep on software project quality. Vilakshan: The XIMB Journal of Management, 10(1). Weiler, H.N., 2000. States, markets and university funding: new paradigms for the reform of higher education in Europe. Compare: A Journal of Comparative and International Education, 30(3), pp.333-339. 